\title{
HBV Genotyping and Phylogenetic Analysis through Multiplex PCR Using Type Specific Primer Pairs in Pakistani Population
}

\section{Javed Iqbal ${ }^{1,2 *}$, Abida Raza ${ }^{3}$ and Jabar Zaman Khan Khattak ${ }^{1}$}

${ }^{1}$ Department of Bioinformatic \& Biotechnology, International Islamic University, Islamabad, Pakistan

${ }^{2}$ School of Life Sciences, Shaanxi Normal University, Xian, P.R China

${ }^{3}$ Nuclear Medicine, Oncology and Radiotherapy Institute [NORI], Islamabad, Pakistan

\section{Abstract}

Background: Hepatitis B virus causing acute and chronic hepatocellular carcinoma relics a serious health issue affecting more than 350 million people worldwide. Geographically, nine genotypes of HBV have been identified so far. Four open reading frames named (ORF P, S, F and X) renders it to specifically targets hepatocyte cells. Additionally, reverse transcription process present in the life cycle of HBV caused four order higher mutation rates as compared to adenovirus. The structural and functional differences between HBV genotypes are the mainstay to severity, complications, treatment and possibly vaccination against the virus. Hepatitis B genotyping is important for assessing its clinical implications and geographical distribution, but the sub-genotypes have been found useful for determination of specific genomic markers related to hepatocarcinogenesis and medical therapies. In Pakistan, there is no reported data available on molecular evolutionary analysis of HBV. A study was, therefore, much needed to evaluate the spectra of dominant strains prevalent here.

Objectives: This study was aimed to figure out the prevalence of HBV genotypes among population in Pakistan. In this research, we focused to find out the new strains and sub genotypes of HBV. Pakistan is one of the HBV endemic countries but there is no data on subgenotypes and their recombination or the phylogenetic relatedness of the virus endemic in the country. The present study was carried out in this perspective. This study will help future researcher to study some other aspects of HBV related strains in Pakistan and also about its medical therapies.

Place and duration of study: The present study was carried out at Polymerase Chain Reaction (PCR) lab, Nuclear Medicine, Oncology and Radiotherapy Institute [NORI], Islamabad, and the samples were collected between September 2012 to February 2014

Study design: A total of 450 Hepatitis B surface antigen HBsAg and HBV DNA positive samples were collected in the first step during the period of September 2012 to February 2014 and sent to Nuclear Medicine Oncology and Radiotherapy Institute [NORI], for further analysis. All the samples were genotyped by type specific nested PCR primer pair method for $8 \mathrm{HBV}$ genotypes from $\mathrm{A}$ through $\mathrm{H}$. The patients were randomly selected irrespective of their age and gender and a written consent (parental consent in case of less than 18 years of age) was obtained. The study was approved by ethical review committee. In our research, we have used the type specific primer technique to find out the dominant strain in Pakistani populations and furthermore its phylogenetic analysis with reference sequences retrieved from NCBI databases.

Results: Our results showed a direct relationship between viral load and identified genotypes and pinpointed that genotype $\mathrm{D}$ is the most pre-dominant genotype and prevailing in high proportions among all genotypes in Pakistani population. Mix HBV genotype infections of genotype A with B \& C, D with B and C constitute about 17 percent of all the samples. Subgenotypes of different HBV strains have been identified on the basis of differences in the complete nucleotide sequences. Positive PCR results were repeated twice for confirmation. Furthermore, phylogenetic analysis revealed a homology between our reported sequences and reference sequences. The phylogenetic method showed that genotypes/sub-genotypes varies in the geographical areas and correlate strongly with ethnicity.

Conclusion: Genotype D was identified and come out to be the most dominant genotype in Pakistani community showing sub-genotypes of D1 \& D3 in our study. Genotype A and D are present as co-infection with each other and contributed as the second prevailing genotypic group. Additionally, phylogenetic analysis revealed that genotypes varies in the geographical areas and correlate strongly with reference sequences from NCBI.

Keywords: Hepatocellualr carcinoma; Viral genome; Real time PCR; Melting curve analysis

\section{Introduction}

Hepatitis B virus (HBV) is one of those agents causing acute and chronic hepatitis in human beings. HBV infection relics a serious and universal health issue throughout the world, with more than 350 million people are chronically infected from this disease throughout the world [1].

HBV genome is of approximately 3,200 base pairs having partially circular duplex DNA molecule. The circularity of HBV DNA is maintained by 5 ' cohesive ends. The mRNA is synthesized by negative DNA strand of HBV. Four overlapping open reading frames are present in HBV genome with condensed coding region as well. These ORF are named as $\mathrm{P}, \mathrm{S}, \mathrm{F}$, and $\mathrm{X}$. The first ORF P codes for viral polymerase and terminal protein present on negative strand (DNA polymerase activity,

*Corresponding author: Javed Iqbal, School of Life Sciences, Shaanxi Normal University, Xian, P.R China, Tel: (+52) 477-2674900; E-mail: imjavedkhan89@gmail.com

Received March 09, 2016; Accepted May 22, 2016; Published May 27, 2016

Citation: Iqbal J, Raza A, Khattak JZK (2016) HBV Genotyping and Phylogenetic Analysis through Multiplex PCR Using Type Specific Primer Pairs in Pakistan Population. J Bacteriol Parasitol 7: 276. doi:10.4172/2155-9597.1000276

Copyright: (c) 2016 lqbal J, et al. This is an open-access article distributed unde the terms of the Creative Commons Attribution License, which permits unrestricted use, distribution, and reproduction in any medium, provided the original author and source are credited. 
Reverse transcriptase and RNase $\mathrm{H})$. Open reading frame $\mathrm{S}$ also known as pre-S, codes for those type of surface viral glycoprotein such as HBsAg, hepatitis B antigen surface that's commonly combine with cell receptor and facilitate ingress of virus into the cells [2].

Nine genotypes of HBV have been recognized on the basis of divergence in the whole DNA genome sequence of HBV [3]. HBV Genotypes show a prominent geographical pattern in their distribution. Genotype A is predominant in North America and Northern Europe as well as in the same parts of Africa. Genotypes B and C are more regular in the region of South East Asia [4-6]. Genotype D is found commonly all over the world [5]. Genotype $\mathrm{E}$ is detected from western and southern Africa while F genotype is reported in south and Central America [7]. Genotype $\mathrm{G}$ has been detected in America and France [8].

HBV infection leads to hepatocirrhosis and liver cancer. Reverse transcription process present in the life cycle of HBV causing four orders higher mutation rate as compared to other adenoviruses and it's because of lack of proof reading activity of reverse transcriptase enzyme of virus [9]. Genomic wide association study (GWAS) reported a new genetic locus contributing in HBV associated hepatocellular carcinoma (HCC) [10]. Locus (rs 17401966) a single nucleotide polymorphism (SNP) on chromosome 1p36.22 is the member of kinesin family named (KIF1B) and is present in the intronic region of the gene. Two SNPs adjacent to this locus (rs 12734551, rs 3748578) showed association to hepatocellular carcinoma risk (HCC) within hepatitis B infected patients.

These SNPs were found to be in linkage disequilibrium state (LDS) with locus rs 17401966 [10]. Cytogenetic studies also confirmed this association between 1p36.22 chromosomal region and numerous different types of cancers including basal carcinoma by the frequent loss of chromosomal region $[11,12]$.

The regions where deletion occurs commonly are pre core genes, pre $\mathrm{S}$ region, and the region of $\mathrm{X}$ gene involved with basic core promoter region (BCP) [13]. These deletions are frame shift deletions and are believed to be linked with the progression of viral hepatitis. These deletions are frequently detected by sero-conversion from HBAsg to anti-HBe [14]. Nucleotide deletions of 1762 and 1764 in the codon region of 130 and 131 of $\mathrm{X}$ gene are reported to be common in hepatocellular carcinoma patients $[15,16]$. Although, deletions also occurred in the pre $S$ region leading to the production of truncated HBV surface proteins that get accumulated in endoplasmic reticulum (ER). The pressure within ER increases due to which expression of cyclin A and host apoptosis suppressor cyclooxygenase-2 occurs $[17,18]$. In one study, they showed miR-15b, an important miRNA during HBV infection and hepatocellular carcinoma development, directly binds hepatocyte nuclear factor 1 (HNF1) mRNA, a negative regulator of HBV Enhancer I, to attenuate HNF1 expression and resulting in transactivation of HBV Enhancer I. This process leads to the enhancement of HBV replication and expression of HBV antigens, including $\mathrm{HBx}$ protein, finally leading to the down-regulated expression of miR-15b in both cell lines and mice in a long cascade of events [3].

Hepatitis B virus, the main form of liver cirrhosis has been detected by various HBV detection techniques which differ from each other according to specificity and sensitivity. Among these detection techniques, one reliable method used for HBV detection is from sequencing and phylogenetic analysis.

Various methods for hepatitis B virus genotyping have been reported separately from nucleotide sequencing, including melting curve analysis [19,20], line probe assays [21], PCR restriction fragment length polymorphism (PCR-RFLP) [22], type specific primers PCR technique [23], Hybridization assays and serological assays of DNA [21] and enzyme linked immunosorbant assay-based method [24]. HBV DNA can also be sequenced through commercial available sequencing kit (TRUGENE HBV Genotyping Sequencing Kit; Siemens Medical Solutions Diagnostic, USA) [25].

Up to 2007, the total numbers of HBV sequences available in public genomic databases were 866 deposited in GeneBank, EMBL and DDJB. All these sequences were contributed by 46 countries and the rate of infection and epidemic of HBV appears more severe in Asia. China contributed much more in increasing public genomic databases due to largest infected population [26].

In this study, an efficient, more precise and more elaborated Real Time PCR based method was used so that we can find out HBV DNA quantification (viral loads) and genotyping with differentiation through A to $G$. The results showed uniformity with current viral load quantitation, proficient genotyping and sequencing. The PCR method provides a useful means of rapid and inexpensive diagnosis of $\mathrm{HBV}$ genotypes with different geographical distributions.

\section{Material and Methods}

\section{Blood sample collection}

3-5 ml blood was collected from selected $450 \mathrm{HBV}$ positive patients within standard EDTA collection tubes. The whole blood was stored not longer than 6 hours at $4-25^{\circ} \mathrm{C}$. The patients were randomly selected irrespective of their age and gender and a written consent (parental consent in case of less than 18 years of age) was obtained. The study was approved by ethical review committee of the institution.

\section{Plasma separation}

The whole blood samples were centrifuged for 5 minutes at 12,000 rpm (Clinical Centrifuge, Model CH80-2, Germany) at room temperature. Plasma was separated using filter barrier tips. Plasma was transferred into sterile eppendorf tubes after proper labelling and stored at $-20^{\circ} \mathrm{C}$ for further process.

\section{HBV DNA quantification}

Isolation of viral DNA from plasma: The viral DNA was extracted from plasma by using AJ ROBOSCREEN INSTANT virus DNA kit ( $\mathrm{GmbH}$, Germany) according to the manufacturer protocol. The HBV DNA quantification kit ROBOGENE is proposed for quantification of hepatitis B virus (HBV) DNA through real time PCR from human EDTA plasma sample. The extracted viral DNA was stored at $-80^{\circ} \mathrm{C}$ for long time storage before initiation PCR

Viral load quantitation: Viral load quantification was done by RoboGene $^{\oplus}$ HBV Quantification kit (AJ Roboscreen, analytikajena Biosolutions, GmbH, Germany) at NORI. This allows amplifying all known HBV genotypes (A-I) with parallel efficiency by probes applying and primers specific for a subsequence of HBV-S gene encoding HBsAg. Upstream probe is labelled with 5'-end reporter dye (FAM for HBV DNA: Yakima Yellow for IC DNA) and downstream probe is labelled with quencher dye. A three step PCR protocol was followed: Taq activation step at $95^{\circ} \mathrm{C}$ for $4 \mathrm{~min}$, then 50 synthesis cycles at $57^{\circ} \mathrm{C}$ for $1 \mathrm{~min}$, melting at $95^{\circ} \mathrm{C}$ for $30 \mathrm{~s}$, stem formation with fluorescence detection at $45^{\circ} \mathrm{C}$ for $30 \mathrm{~s}$ using Rotor- Gene ${ }^{\mathrm{Tm}} 3000$, Corbett Research, Australia. Data collected in the form of sigmoid growth curves was analyzed according to manufacturer's instructions keeping in view the parameters of slope correction and value, thresholds, CT value of IC DNA and R value, HBV DNA concentration which is expressed in IU/ 
$\mathrm{ml}$. Quantitation standards ranged from $5 \times 10^{2}$ to $5 \times 10^{7} \mathrm{IU} / \mathrm{ml}$ were provided along with the kit (Tables 1 and 2).

Agarose gel electrophoresis: For the purpose of electrophoresis, we prepared agarose gel with $2 \%$ concentration. Run HBV DNA fragments were separated by means of agarose gel electrophoresis via agarose at concentrations of $2 \% \mathrm{w} / \mathrm{v}$ in $1 \mathrm{x}$ TAE buffer. The gel was run in 1x TAE buffer for 45 minutes at $100 \mathrm{~V}$. The size of DNA fragments were compared with GeneRulerTM 50bp DNA ladder (MBI Fermentas, Life Sciences, Catalogue \# SM 0373).

DNA sequencing: Selected samples were run on agarose to identify the genotyping. These were then amplified in higher volume $50 \mu \mathrm{l}$ and were run on $2 \%$ agarose gel. The bands were visualized under gel documentation system (BioRad Gel Doc-XR, USA) and were cut using personal protective equipment under UV. DNA was eluted from the gel using GeneGETTM Genomic DNA purification mini kit (Fermentas Biosciences).

Sequence analysis: Purified samples of selected genotypes were analyzed by sequencing using $\mathrm{ABI}$ automated sequencer. The sequences of nucleotide were viewed using software version 2.0 of chromas. Electropherograms of each sample were identified first, analyzed and ambiguities in the data sequences were resolved by comparison of the results of forward and reverse primers with those sequences of $\mathrm{HBV}$ obtained from NCBI database.

BLAST analysis: The sequences were submitted as query sequences to BLAST (on line available program at website http://www.ncbi.nlm. nih.gov/BLAST/). After then, different countries sequences were aligned with our subject sequences to obtained the define length of our subject sequence. The BLAST was done to identify the similarity of HBV sample sequences with the reported databases.

Reference sequence retrieval: Reported reference sequences of HBV were retrieved for construction of phylogenetic tree. From phylogenetic tree, the verification of unknown sample can be easily found. Following accession numbers and website was used to retrieve reference sequences. Website: http://www.ncbi.nlm.nih.gov). Sequence of each genotype was retrieved to construct a phylogenetic reference tree (Table 3).

\begin{tabular}{|l|l|c|c|}
\hline Primers & Sequences $\mathbf{( 5}^{\prime} \mathbf{3}^{\prime}$ ) & Base Position & Polarity \\
\hline PI-A & TCACCATATTCTTGGGAACAACA & $2823-2845$ & Sense \\
\hline SI-2 & CGAACCACTGAACAAATGGC & $685-704$ & Antisense \\
\hline
\end{tabular}

Table 1: Primers Sequences Used In Study for the Amplification of Hepatitis $B$ Virus (First Round PCR).

\begin{tabular}{|c|c|c|c|}
\hline Primers & Sequences (5'-3') & $\begin{array}{c}\text { Base } \\
\text { Position }\end{array}$ & Polarity \\
\hline & Mixture A & & \\
\hline B2 & GGCTCMAGTTCMGGAACAGT & $67-86$ & Sense \\
\hline BAIR & CTCGCGGAGATTGACGAGATGT & $113-134$ & Antisense \\
\hline BBIR & CAGGTTGGTGAGTGACTGGAGA & $324-345$ & Antisense \\
\hline \multirow[t]{2}{*}{$\mathrm{BCIR}$} & GGTCCTAGGAATCCTGATGTTG & $165-186$ & Antisense \\
\hline & Mixture B & & \\
\hline BD1 & GCCAACAAGGTAGGAGCT & 2979-2996 & Sense \\
\hline BE1 & CACCAGAAATCCAGATTGGGACCA & 2955-2978 & Sense \\
\hline BF1 & GYTACGGTCCAGGGTTACCA & $3032-3051$ & Sense \\
\hline $\mathrm{B} 2 \mathrm{R}$ & GGAGGCGGATYTGCTGGCAA & 3078-3097 & Antisense \\
\hline
\end{tabular}

An "M" represents a nucleotide that could be either an A or a C; a " $Y$ " represents a nucleotide that could be either a $\mathrm{C}$ or a $\mathrm{T}$;

Table 2: Sequences of Primers for HBV Genotyping Used By Nested PCR (Second Round PCR).
Phylogenetic tree analysis: Phylogenetic tree from HBV sequences were generated by neighbor joining algorithm, using CLC workbench software (www.clcbio.com). The sequences were aligned to draw a consensus sequences and those consensus sequences were submitted to NCBI. The phylogenetic tree was constructed from reported sequences. The amino acid sequences were analyzed for substitution of conservative and non-conservative mode by using software CLC workbench, parentage of sequence comparison of both nucleotides and amino acids were done by using cluster $\mathrm{W}$ software.

\section{Results}

\section{Viral load quantitation results}

Viral load quantification was done by RoboGene ${ }^{\circledR}$ HBV Quantification kit (AJ Roboscreen, analytikajena Biosolutions, GmbH, Germany) at NORI. A three-step PCR protocol was followed using Rotor- Gene ${ }^{\text {rm }} 3000$, Corbett Research, Australia. Data collected in the form of sigmoid growth curves was analyzed keeping in view the parameters of slope correction and value, thresholds, CT value of IC DNA and R value, HBV DNA concentration was measured in IU/ $\mathrm{ml}$ (Tables 4 and 5).

Standard curves and STD ranges along with given concentration and calculated concentrations are given below in table 4 . The viral load was calculated based on fluorescence based detection of probes that were labelled with different reporter dyes.

The following table (Table 6) shows the viral load calculated through Real Time PCR using eight standard along with given concentration and calculated concentrations. The gender description and age are also mentioned. It indicate that the high viral load exist in sample collected for genotyping purpose.

First round PCR was performed using outer specific primers PI-A and SI-2, maintaining thermo-cycler parameters. The amplified products were run on $2 \%$ agarose gel with GeneRuler ${ }^{\mathrm{TM}} 100 \mathrm{bp}$ DNA ladder (Fermentas, Life Sciences) and observed under GEL DOC XR System (BIO-RAD, Applied Bioscience). The following figures show the results of first round PCR (Figures 1A and 1B).

\begin{tabular}{|c|c|c|c|c|c|c|c|}
\hline $\begin{array}{c}\text { Sr. } \\
\text { No }\end{array}$ & $\begin{array}{c}\text { Accession } \\
\text { No }\end{array}$ & $\begin{array}{c}\text { HBV } \\
\text { Genotype }\end{array}$ & $\begin{array}{c}\text { Country } \\
\text { Origin }\end{array}$ & $\begin{array}{c}\text { Sr. } \\
\text { No }\end{array}$ & $\begin{array}{c}\text { Accession } \\
\text { No }\end{array}$ & $\begin{array}{c}\text { HBV } \\
\text { Genotype }\end{array}$ & $\begin{array}{c}\text { Country } \\
\text { Origin }\end{array}$ \\
\hline $\mathbf{1}$ & AM282986 & A & USA & $\mathbf{2 1}$ & JN604278 & D & USA \\
\hline $\mathbf{2}$ & JX507200 & B & Panama & $\mathbf{2 2}$ & JN370953 & D & USA \\
\hline $\mathbf{3}$ & JN104438 & C & USA & $\mathbf{2 3}$ & GU570525 & E & UK \\
\hline $\mathbf{4}$ & JQ514458 & D & India & $\mathbf{2 4}$ & GQ161830 & E & UK \\
\hline $\mathbf{5}$ & AY303894 & E & Gambia & $\mathbf{2 5}$ & GQ161805 & E & UK \\
\hline $\mathbf{6}$ & JX849636 & F & Italy & $\mathbf{2 6}$ & GQ161818 & E & UK \\
\hline $\mathbf{7}$ & CS409748 & G & USA & $\mathbf{2 7}$ & GQ161822 & E & UK \\
\hline $\mathbf{8}$ & CS388980 & H & USA & $\mathbf{2 8}$ & JX868564 & D & Pakistan \\
\hline $\mathbf{9}$ & DQ297903 & A & India & $\mathbf{2 9}$ & JX868564 & D & Pakistan \\
\hline $\mathbf{1 0}$ & JQ514338 & D & India & $\mathbf{3 0}$ & FJ670514 & D & Pakistan \\
\hline $\mathbf{1 1}$ & JQ514406 & C & India & $\mathbf{3 1}$ & EF584653 & D & Pakistan \\
\hline $\mathbf{1 2}$ & JQ514438 & D & India & $\mathbf{3 2}$ & FJ670507 & D & Pakistan \\
\hline $\mathbf{1 3}$ & JX090637 & D & Russia & $\mathbf{3 3}$ & HQ385240 & D & Sudan \\
\hline $\mathbf{1 4}$ & EU594418 & D & Russia & $\mathbf{3 4}$ & AB104722 & D & Egypt \\
\hline $\mathbf{1 5}$ & EU594414 & D & Russia & $\mathbf{3 5}$ & AB104715 & D & Egypt \\
\hline $\mathbf{1 6}$ & JX090722 & D & Russia & $\mathbf{3 6}$ & HQ385233 & D & Egypt \\
\hline $\mathbf{1 7}$ & JX090648 & D & Russia & $\mathbf{3 7}$ & AB263405 & D & Mongolia \\
\hline $\mathbf{1 8}$ & EU769261 & G & USA & $\mathbf{3 8}$ & AB263412 & D & Mongolia \\
\hline $\mathbf{1 9}$ & EU769256 & A & USA & $\mathbf{3 9}$ & AB263410 & D & Mongolia \\
\hline $\mathbf{2 0}$ & JN604206 & D & USA & $\mathbf{4 0}$ & AB644317 & D & Indonesia \\
\hline & & & & & & \\
\hline
\end{tabular}

Table 3: Reference Sequences of HBV Pre-S1 Region. 
Citation: Iqbal J, Raza A, Khattak JZK (2016) HBV Genotyping and Phylogenetic Analysis through Multiplex PCR Using Type Specific Primer Pairs in Pakistani Population. J Bacteriol Parasitol 7: 276. doi:10.4172/2155-9597.1000276

\begin{tabular}{|c|c|c|c|c|c|c|c|}
\hline No. & Colour & Name & Type & Ct & $\begin{array}{c}\text { Given Conc } \\
\text { (copies/ul) }\end{array}$ & $\begin{array}{c}\text { Calc Conc } \\
\text { (copies/ul) }\end{array}$ & $\%$ Var \\
\hline 1 & & STD1 & Standard & 15.51 & $50,000,000$ & $48,386,650$ & $3.2 \%$ \\
\hline 2 & & STD2 & Standard & 15.51 & $5,000,000$ & $48,386,650$ & $3.2 \%$ \\
\hline 3 & & STD3 & Standard & 21.88 & 500,000 & 522,595 & $4.5 \%$ \\
\hline 4 & & STD4 & Standard & 15.51 & 125,000 & $48,386,650$ & $3.2 \%$ \\
\hline 5 & & STD5 & Standard & 25.19 & 50,000 & 49,712 & $0.6 \%$ \\
\hline 6 & & STD6 & Standard & 27.09 & 12,500 & 12,890 & $3.1 \%$ \\
\hline 7 & & STD7 & Standard & 31.71 & 2,500 & 482 & $3.6 \%$ \\
\hline 8 & & STD8 & Standard & 15.51 & 500 & 2,500 & $3.2 \%$ \\
\hline 9 & & NTC & NTC & & & & \\
\hline
\end{tabular}

Table 4: STD Ranges with given and calculated concentration (no of copies/ul).

\begin{tabular}{|l|l|}
\hline $\begin{array}{l}\text { Cycle } \\
\text { Hold at } 95^{\circ} \mathrm{C}, 4 \mathrm{~min} 0 \mathrm{sec}\end{array}$ \\
\hline Cycling (50 repeats) & Step 1 at $95^{\circ} \mathrm{c}$, hold $15 \mathrm{sec}$ \\
\hline & $\begin{array}{l}\text { Step } 2 \text { at } 45^{\circ} \mathrm{c}, \text { hold } 15 \mathrm{sec} \text {, acquiring to Cycling A } \\
\text { ([Red][4][4],[Green][1][1],[Yellow][2][2],[Orange] } \\
[3][3])\end{array}$ \\
\hline & Step 3 at $57^{\circ} \mathrm{c}$, hold $40 \mathrm{sec}$ \\
\hline & Table 5: Cycling Profile \\
\hline
\end{tabular}

\begin{tabular}{|r|c|c|c|c|c|}
\hline $\begin{array}{c}\text { Serial } \\
\text { No }\end{array}$ & PRN No & Gender & Age & $\begin{array}{c}\text { Allotted Tube } \\
\text { No }\end{array}$ & Viral Load \\
\hline $\mathbf{1}$ & $015956 / 12$ & Female & 24 & 3 & $5.7 \times 10^{8}$ \\
\hline $\mathbf{2}$ & $026283 / 12$ & Male & 22 & 5 & $4.2 \times 10^{6}$ \\
\hline $\mathbf{3}$ & $026047 / 12$ & Female & 50 & 6 & $6.1 \times 10^{5}$ \\
\hline $\mathbf{4}$ & $024232 / 12$ & Male & 47 & 7 & $1.6 \times 10^{7}$ \\
\hline $\mathbf{5}$ & $026137 / 12$ & Male & 19 & 8 & $1.2 \times 10^{8}$ \\
\hline $\mathbf{6}$ & $009221 / 12$ & Female & 55 & 10 & $2.5 \times 10^{7}$ \\
\hline $\mathbf{7}$ & $026652 / 12$ & Male & 03 & 11 & $3.7 \times 10^{7}$ \\
\hline $\mathbf{8}$ & $017661 / 10$ & Female & 43 & 12 & $1.2 \times 10^{5}$ \\
\hline $\mathbf{9}$ & $026986 / 12$ & Male & 15 & 13 & $1.4 \times 10^{7}$ \\
\hline $\mathbf{1 0}$ & $027188 / 12$ & Male & 21 & 14 & $7.7 \times 10^{6}$ \\
\hline $\mathbf{1 1}$ & $027957 / 12$ & Male & 30 & 16 & $4.0 \times 10^{8}$ \\
\hline $\mathbf{1 2}$ & $028112 / 12$ & Male & 10 & 17 & $1.4 \times 10^{8}$ \\
\hline $\mathbf{1 3}$ & $028422 / 12$ & Male & 22 & 18 & $6.6 \times 10^{7}$ \\
\hline $\mathbf{1 4}$ & $029997 / 12$ & Male & 32 & 19 & $1.4 \times 10^{9}$ \\
\hline $\mathbf{1 5}$ & $030043 / 12$ & Female & 28 & 20 & $1.8 \times 10^{9}$ \\
\hline $\mathbf{1 6}$ & $030282 / 12$ & Male & 13 & 21 & $1.9 \times 10^{9}$ \\
\hline $\mathbf{1 7}$ & $007728 / 10$ & Female & 20 & 22 & $1.9 \times 10^{7}$ \\
\hline $\mathbf{1 8}$ & $029722 / 12$ & Female & 38 & 23 & $1.1 \times 10^{9}$ \\
\hline $\mathbf{1 9}$ & $030578 / 12$ & Male & 15 & 24 & $2.6 \times 10^{8}$ \\
\hline $\mathbf{2 0}$ & $030691 / 12$ & Male & 30 & 25 & $1.3 \times 10^{9}$ \\
\hline & & Table 6: Viral Load calculated by Real Time PCR. \\
\hline
\end{tabular}

\section{Nested PCR product results}

For finding out the genotypes of various HBV samples, we performed the nested PCR using inner primer pair common with the universal sense primer B2 with mixture I for genotypes A to C. The common antisense primer B2R is used with mixture B to identify genotypes
$\mathrm{D}, \mathrm{E}$ and $\mathrm{F}$. The nested products of PCR were run on $2 \%$ agarose gel with GeneRuler ${ }^{\mathrm{TM}} 50$ bp DNA ladder (Fermentas, Life Sciences) run as marker. The $69 \mathrm{bp}$ and $119 \mathrm{bp}$ DNA bands were obtained in mixture A and $\mathrm{B}$ respectively (Figures $2 \mathrm{~A}$ and $2 \mathrm{~B}$ )

\section{Relationship between viral load and genotypes}

A clear relationship was observed between the viral load and identified genotypes. The genotypes were found by multiplex PCR using type specific primers pair. The Table 7 shows that genotype D is prevailing in high proportion among all genotypes in Pakistan. In some samples, mixed genotype $\mathrm{A}+\mathrm{D}$ was also observed. The high viral load was reported from dominant genotypes $\mathrm{D}$ and $\mathrm{A}+\mathrm{D}$. The identified genotypes are further confirmed by sequence analysis.

\section{Construction of phylogenetic tree}

To elucidate the results of HBV genotype $\mathrm{D}$, sequencing was performed. The NORI-HBV1 to NORI-HBV10 sequence isolates were subjected to NCBI for blast. The phylogenetic tree of sequences was constructed by use of CLC sequence view software through neighbor joining method compared with forty reference sequences obtained from NCBI. In phylogenetic tree, the sequences are grouped into three clusters (Figure 3). Cluster one contained our reported sequences

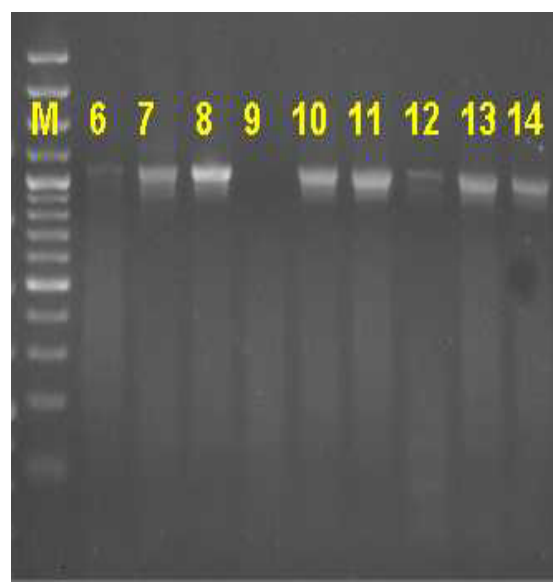

Figure 1(A): Amplified products of First Round PCR Lane 1 100kb DNA ladder run as Marker Fermentas), Lane 2, 3, 4, 6, 7, 8, 9, 10, (>1000 bp bands) confirming DNA in samples. Lane 5: sample having no DNA.

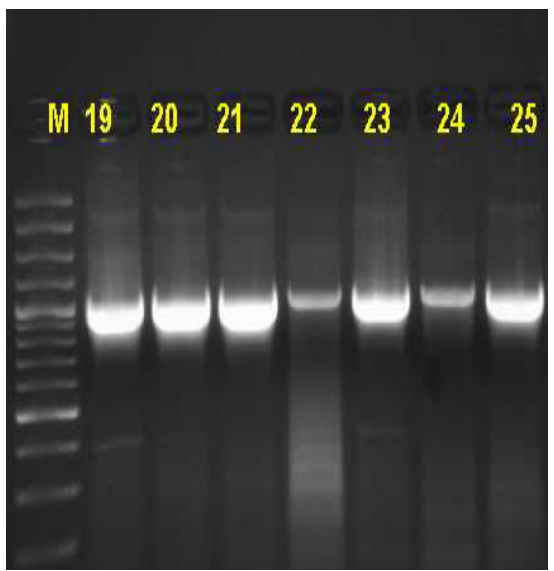

Figure 1(B): Amplified products of First Round PCR Lane 1: 100kb DNA ladder (Fermentas), Lane 2-8: Samples having amplified DNA (> $1000 \mathrm{~kb}$ in size). 
Citation: Iqbal J, Raza A, Khattak JZK (2016) HBV Genotyping and Phylogenetic Analysis through Multiplex PCR Using Type Specific Primer Pairs in Pakistani Population. J Bacteriol Parasitol 7: 276. doi:10.4172/2155-9597.1000276

Page 5 of 9

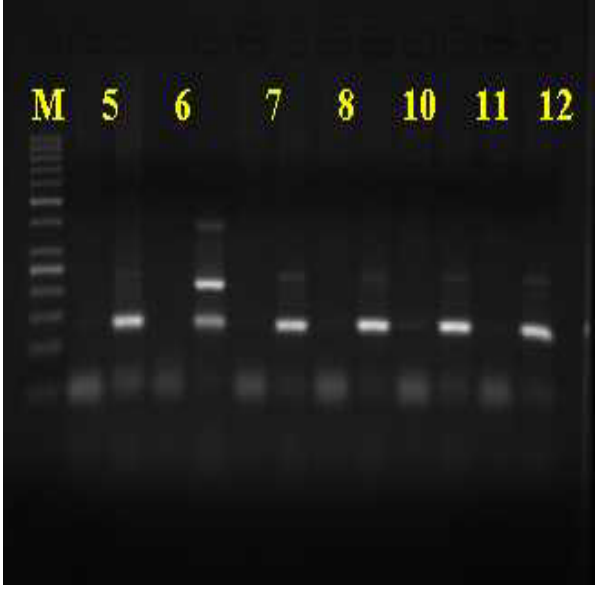

Figure 2(A) : Nested PCR Products (Second Round PCR) Lane 1: GeneRulerTM 50bp DNA ladder (Fermentas, Life Sciences) run as marker. Mix I \& 2 run side by side. Lane 2, 4, 6, 8, 10, 12: PCR product of HBV positive samples with $119 \mathrm{bp}$ size fragments (Genotype D).

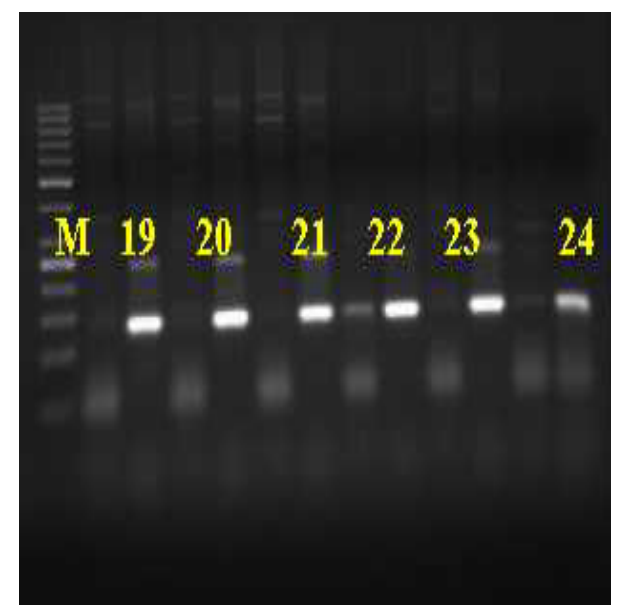

Figure 2(B) : Nested PCR Products (Second Round PCR) Lane 1: GeneRulerTM 50bp DNA ladder (Fermentas, Life Sciences) run as marker Mix I \& 2 run side by side. Lane 2-12: PCR product of HBV positive samples with $119 \mathrm{bp}$ size fragment (Genotype D).

NORI-HBV1, NORI-HBV2, NORI-HBV3, NORI-HBV8 of genotype $\mathrm{D}$ and the reference sequences of genotype D from UK, USA, Russia and India. Two sequences NORI-HBV5, NORI-HBV7 of genotype $\mathrm{D}$ are present in second cluster and show homology with sequences of genotype D from India, Russia, Indonesia and Egypt. Third cluster consist of reference sequences of genotype D from Turkey, Iran, USA and Russia with our reported sequences of genotype D NORI-HBV4, NORI-HBV6, NORI-HBV9 and NORI-HBV10.

\section{Phylogenetic tree two constructions}

Phylogenetic tree two was constructed by taking reference sequences of different genotypes from various countries. These sequences taken from NCBI were blast with our current sequences. All sequences are grouped into three clusters (Figure 4).

NORI-HBV9 sequence is present in cluster one and it shows homology with the sequences from India (Genotype D), UK (Genotype E), USA (Genotype A) and Italy (Genotype E). Cluster two comprised

\begin{tabular}{|c|c|c|c|c|c|}
\hline $\begin{array}{l}\text { Serial } \\
\text { No }\end{array}$ & $\begin{array}{c}\text { Allotted } \\
\text { Tube } \\
\text { No }\end{array}$ & Sequencing No & Colour & Viral Load & Results \\
\hline 1 & 3 & HB31 & Red & $5.7 \times 10^{8}$ & A\&D \\
\hline 2 & 5 & HB32 & Red & $4.2 \times 10^{6}$ & D \\
\hline 3 & 6 & HB33 & Red & $6.1 \times 10^{5}$ & D \\
\hline 4 & 7 & HB34 & Red & $1.6 \times 10^{7}$ & D \\
\hline 5 & 8 & HB35 & Red & $1.2 \times 10^{8}$ & D \\
\hline 6 & 10 & HB36 & Red & $2.5 \times 10^{7}$ & D \\
\hline 7 & 11 & HB37 & Red & $3.7 \times 10^{7}$ & D \\
\hline 8 & 12 & HB38 & Red & $1.2 \times 10^{5}$ & D \\
\hline 9 & 13 & HB39 & Red & $1.4 \times 10^{7}$ & A\&D \\
\hline 10 & 14 & HB40 & Red & $7.7 \times 10^{6}$ & A\&D \\
\hline 11 & 16 & HB41 & Red & $4.0 \times 10^{8}$ & A\&D \\
\hline 12 & 17 & HB42 & Red & $1.4 \times 10^{8}$ & A\&D \\
\hline 13 & 18 & HB43 & Red & $6.6 \times 10^{7}$ & A\&D \\
\hline 14 & 19 & HB44 & Red & $1.4 \times 10^{9}$ & D \\
\hline 15 & 20 & HB45 & Red & $1.8 \times 10^{9}$ & D \\
\hline 16 & 21 & HB46 & Red & $1.9 \times 10^{9}$ & D \\
\hline 17 & 22 & HB47 & Red & $1.9 \times 10^{7}$ & D \\
\hline 18 & 23 & HB48 & Red & $1.1 \times 10^{9}$ & D \\
\hline 19 & 24 & HB49 & Red & $2.6 \times 10^{8}$ & D \\
\hline 20 & 25 & HB50 & Red & $1.3 \times 10^{9}$ & D \\
\hline
\end{tabular}

Table 7: Genotype Find out by Multiplex PCR and its Relationship with the Vira Load.

of reference sequences from USA and Pakistan showing genotype D, E. It contained our six sequences abbreviated as NORI-HBV1, NORIHBV2, NORI-HBV3, NORI-HBV5, NORI-HBV7, and NORI-HBV8.

Third cluster contained our two sequences abbreviated NORIHBV4, NORI-HBV6 and aligned with genotype D sequence from USA and Pakistan.

\section{Discussion}

The aim of the study was to find out HBV dominant strain and genotyping via a modern, precise and elaborate method of HBV genotyping. The phylogenetic analysis was performed to allow specific fortitude and discrimination of all recognized genotypes. The HBV genotypes are disseminated geographically but its virulence and pathogenicity vary from each region. Finding HBV genotype is important to clarify the infection pathway and virulence of virus. Variants may vary in pattern of serological activity, virus replication and treatment response. In fact, genotype $\mathrm{C}$ harbors patient experience a poorer response to treatment than genotype $B$ [27].

In our methodology, genotype A to $\mathrm{F}$ could be detected by only single amplification set for each genotype through nested PCR. In our present study, we focused to find genotype within Pakistani community and found that genotype $\mathrm{D}$ is the most predominant genotype among all known genotypes. Genotype D is frequently linked by pre core mutations that lead to increase the chances of causing cirrhosis and hepatocellular carcinoma [26]. Mutations resulted in CCAAT motif present over the pre-SI gene caused retention of protein $S$ that becomes the more aggressive type of HBV liver related diseases [28]. Due to the lack of unbiased approach, the mutational extent and functional impact of HBV in HCC progression is not studied. The sequencing technologies provide an opportunity to investigate the global extent of this mutation and functional impact of viral integration in the host genome [29]. Keeping in view the fact that, this type of mutant seems to occur frequently in our population. Current antiviral agents can control 


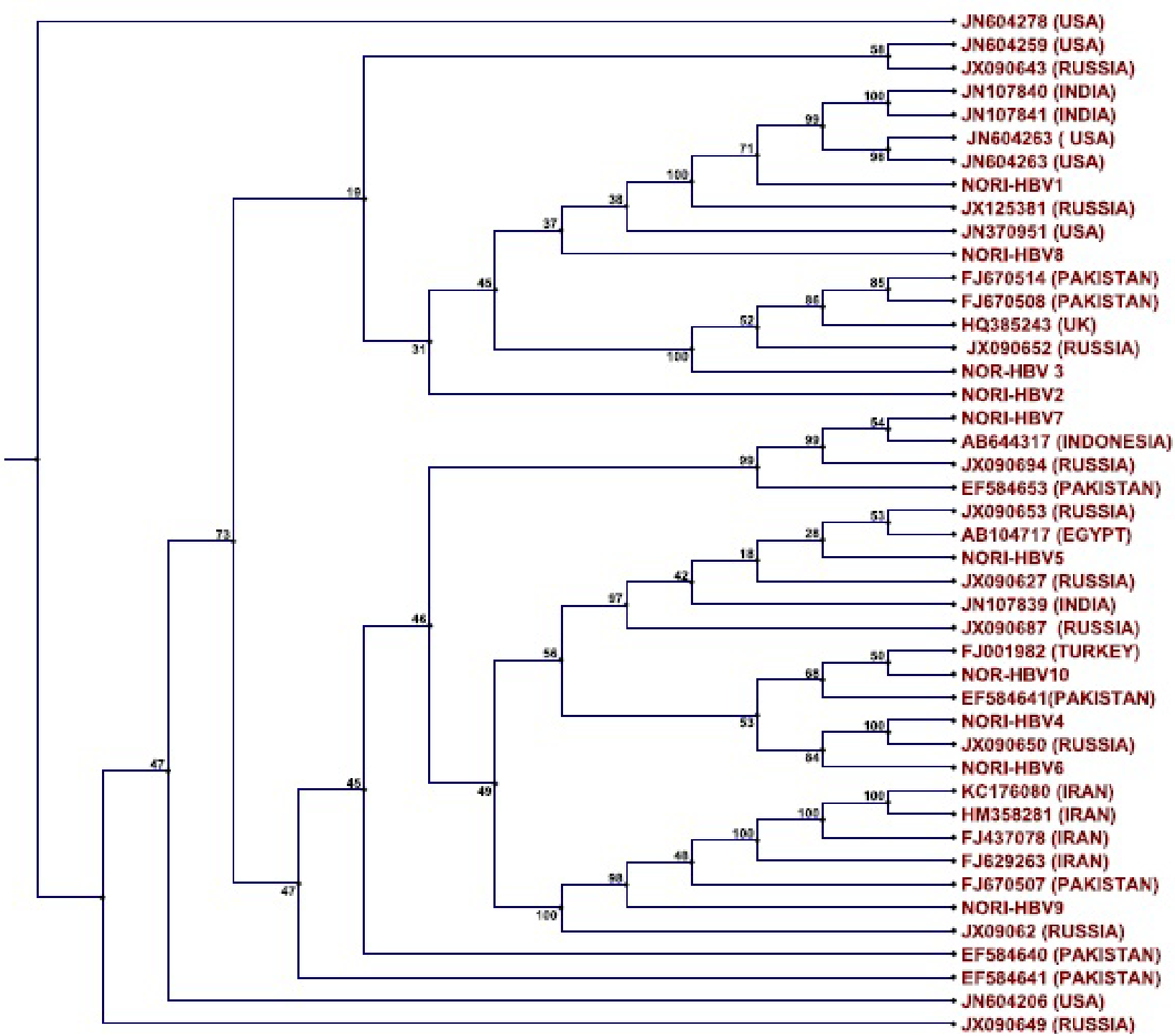

Figure 3: Phylogenetic tree construction: Phylogenetic tree constructed using reference sequences from various countries with our reported sequences and classified into three cluster showing homology among reference and reported sequences.

but not eliminate hepatitis B virus (HBV), because HBV establishes a stable nuclear covalently closed circular DNA (cccDNA). Interferon- $a$ treatment can clear HBV but is limited by systemic side effects. Interferon- $\alpha$ can induce specific degradation of the nuclear viral DNA without hepatotoxicity and propose lymphotoxin- $\beta$ receptor activation as a therapeutic alternative.

Most studies have concluded genotype $\mathrm{D}$, a worse prognosis factor than genotype $\mathrm{B}$ and showed the correlation between hepatocellular carcinoma and the rate development of genotype $\mathrm{C}$. In one study, they showed miR15b which directly binds hepatocyte nuclear factor 1 (HNF1) mRNA, a negative regulator of HBV Enhancer I, to attenuate HNF1 expression and resulting in transactivation of HBV Enhancer I. This process leads to the enhancement of HBV replication and expression of HBV antigens, including $\mathrm{HBx}$ protein, finally leading to the down-regulated expression of miR-15b in both cell lines and mice in a long cascade of events [3]. In contrast to the above facts, some findings suggest the role of sub genotype in HCC development. Genotype C infected patients show recurrence of HCC and metastasis form of liver cancer.
Several methods for HBV genotyping including fragment length polymorphism by restriction enzyme (RFLP), direct sequence analysis and enzyme linked immunosorbent assay (ELISA) was used as the gold standard method but is not suitable for finding mixed genotypes [30]. Our multiplex PCR method used has low cost and is more reliable as compared to other methods for HBV genotyping and reported to be superior for the detection of double infections. Specific genotype primers pair was constructed based on sequences of nucleotide between $\mathrm{S}$ and pre-SI gene. Chen et al. [31] developed to find genotype $\mathrm{A}$ to $\mathrm{F}$ and sub genotypes collectively.

INNO-LiPA HBV assay used for genotyping is a very sensitive method detecting mixed genotypes but it's too much expensive and the result may be affected by a single nucleotide change so it cannot be used for epidemiological purposes on large scale investigation in developing countries like Pakistan. The RFLP and MCA also allow simultaneous genotyping and quantification of HBV. However, the observed accuracy of MCA is $92.3 \%$ and RFLP is of $87 \%$. The results were affected by 


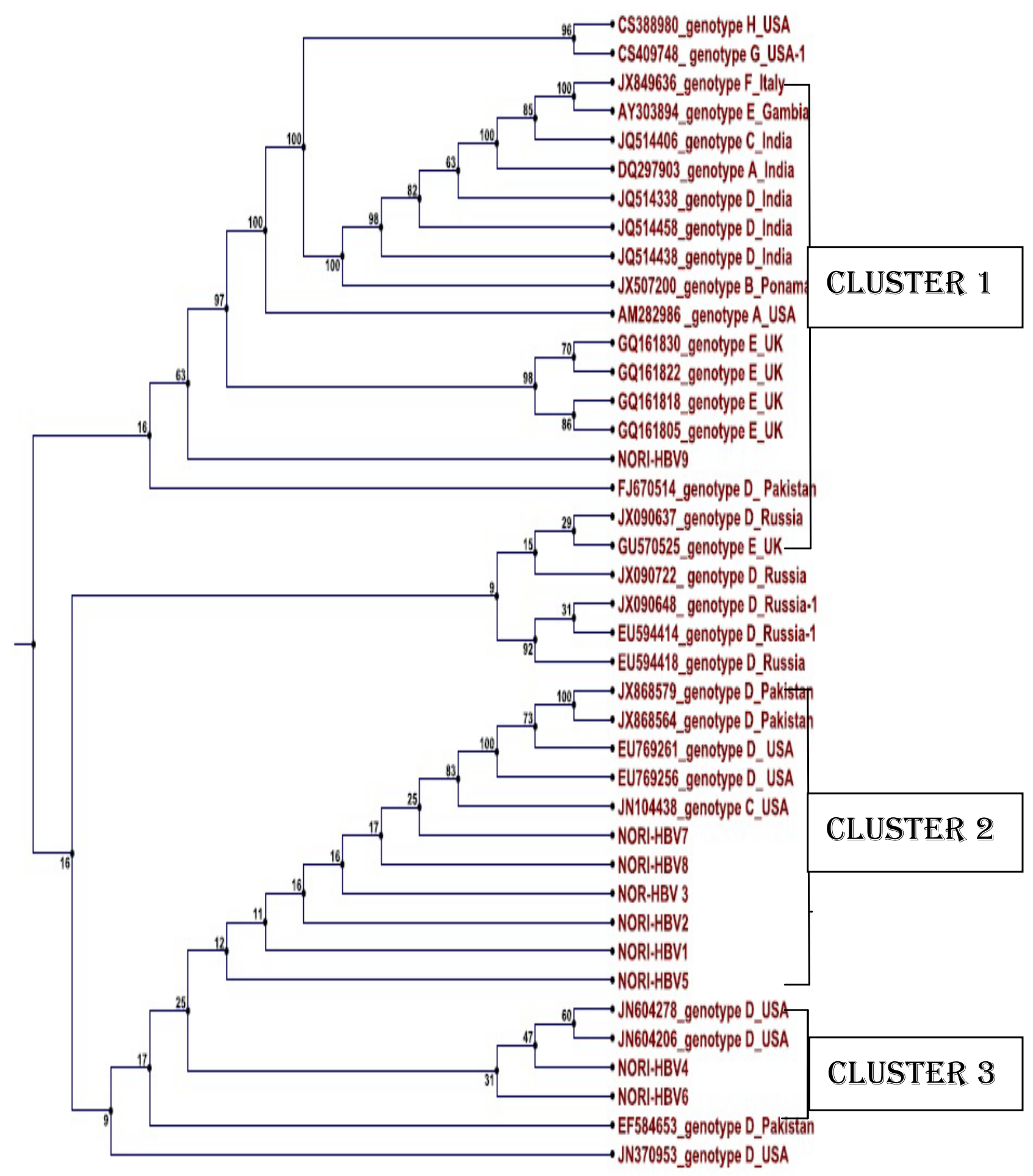

Figure 4: Phylogenetic tree construction: Phylogenetic tree constructed using reference sequences from various countries with our reported sequences and classified into three cluster showing homology among reference and reported sequences.

point mutations that change the melting point leading to uncertain identification of genotype A, C and D.

Usuda et al. [24] developed ELISA technique for the detection of different strains of HBV. Specific monoclonal epitopes were used in this method against pre-S2 region to identify various strain of HBV.
Another method used in most of the clinical laboratories is real time PCR with the help of which both quantification and genotyping can be performed easily. The real time PCR employed fluorescent probes or a dye that firmly attached to the double stranded DNA and aids in the detection and quantification of hepatitis B virus DNA (HBV-DNA). The genotypes are recognized in the samples based on the melting 
curve temperature (Tm). Various genotypes show different values of melting curves. This difference is due to the contemporarily relationship between the target DNA and probe or it can be due to the presence of GC content within the hybridization sequence.

Payunporn et al. [19] showed $90.4 \%$ similarity between sequencing and RFLP while with melting curve procedure, it come out to be $92.3 \%$. Real time PCR system has high sensitivity, superior to oligonucleotide microarray chips and sequencing in detecting mixed genotypes. But the results can be effected by some complications its harbours. Among them, one is single nucleotide polymorphism (SNP) at primer site affecting the sensitivity of this method. The other is low ability of real time to distinguish mixed genotypes due to close proximity between the values.

Peg interferon therapy (PEG-INF) is mainly used against HBV infection and its treatment. The rate of recovery depends to some extent on the presence of its different types. Various finding reported that genotype $\mathrm{B}$ infected patients show better response and early recovery than genotype $\mathrm{C}$. The nucleoside analogues are affected by HBV infection and render it less responsive. In the same way, a genotype infected patients give strong response to peg interferon compared to genotype $\mathrm{D}$. The response rate to peg interferon of genotype $\mathrm{B}$ and $\mathrm{A}$ increases significantly during short-term therapy treatment.

Various methods for HBV sequencing were proposed with the passage of time. One of them is Whole Genome sequencing method which was a standard method for HBV DNA sequencing. Phylogenetic analysis can be performed very easily through this technique but it was not used very widely due to time consuming procedure and it could only identify the dominant genotype from genotypic mixture. The other major condition holding hurdle was that it required more than 100 clones to be screened. Latter an alternative method was developed to whole genome sequencing method by which a single gene can be identified very easily [32]. This method was highly sensitive and sensitivity depends on size of the target sequence.

Studied carried out in USA used commercial available sequencing kit named HBV TRUGENE Genotyping kit. HBV DNA mutations as well as genotypes both were detected simultaneously by this kit. After DNA extraction, polymerase chain reaction was performed to amplify the antigen surface (HBsAg) gene and polymerase gene overlapping with antigen gene [25]. PCR products were added in four reaction tubes and fluorescent based DNA primers were added in those reaction tubes. Bi- directional sequencing was performed to find out the genotype and mutation within HBV genome. Another study in China used type specific nested PCR assay. Inner and outer primers pair of $S$ region used were SF, PR3 and PF, S4R respectively. DNA Analyzer used in this study was of Applied Bio-system (named Applied Bio-system 3730 XL DNA Analyzer). The sequencing was done very efficiently and MEGA 4.0 software was utilized during phylogenetic analysis. All known sequences are deposited in public genomic databases. Through these sequences, one gets knowledge about the geographical distribution of $\mathrm{HBV}$ and the host clinical status. In these databases much contribution are taken part by China.

The multiplex PCR technique is more convenient, precise and elaborates to assist future researchers to use it to identify large scale epidemiological studies within different region of our country by the use of type specific primers. It will also help in the remediation of disease after its identification.

We have not experienced the untypeable results by using type specific primers. The results obtained by genotype specific primers in separate mixture correlate well with those obtained by sequence analysis of HBV samples. Among all the samples, genotype D was the pre dominant one and was identified with a very high viral load [33]. Mixed genotype $\mathrm{A}+\mathrm{D}$ was also present with high viral load but its proportion was very low as compared to genotype $\mathrm{D}$.

Moreover phylogenetic analysis of these samples with published sequences confirmed the sub typing of the strain. Data suggested that although gold standard method for determination of HBV genotype is sequence analysis of phylogenetically informative coding region of the HBV genome and comparison to consensus sequences of known genotypes. Since therapy management decisions have been made on the basis of genotype, not subtype, the overall accuracies of both assays have been considered acceptable. But this knowledge is widely used for research purpose and vaccine development. Genomic sequence analysis followed by phylogenetic analysis for assigning genotypes is time consuming and inconvenient for clinical use and not adapted to clinical studies on large scale routine use. However modified genotype specific primer method is one of the fast typing methods and used in large scale for epidemiological studies.

\section{Conclusion}

Hepatitis B virus is the main causative agent of liver cirrhosis and hepatocellular carcinoma affecting more than 400 million people worldwide. HBV genotypes are geographically distributed throughout the world with specific epidemiological type. In Pakistan, genotype D is the most pre-dominant genotype among all known genotypes occurring in the population and is frequently linked by pre core mutations, increasing the chances of liver cirrhosis and HCC. The second mos prevailing genotype is mixed infection $\mathrm{A}+\mathrm{D}$. Moreover, phylogenetics analysis further confirmed the occurrence and phylogenetics significance of the HBV.

\section{Acknowledgements}

This work was supported by the Nuclear Medicine Oncology and Radiotherapy institute, and International Islamic university, Islamabad, Pakistan. It was also supported by ethical committee of International Islamic University (PC-44000).

\section{References}

1. Günther S (2006) Genetic variation in HBV infection: genotypes and mutants $\mathrm{J}$ Clin Virol 36 1: 3-11.

2. Bruss V (2007) Hepatitis B virus morphogenesis. World J Gastroenterol 13: 65-73

3. Dai X, Zhang W, Zhang H, Sun S, Yu H, et al. (2014) Modulation of HBV replication by microRNA-15b through targeting hepatocyte nuclear factor1. Nucleic Acids Res 42: 6578-6590.

4. Okamoto H, Tsuda F, Sakugawa H, Sastrosoewignjo RI, Imai M, et al. (1988) Typing hepatitis $\mathrm{B}$ virus by homology in nucleotide sequence: comparison of surface antigen subtypes. J Gen Virol 69: 2575-2583.

5. Norder H, Hammas B, Lee SD, Bile K, Couroucé AM, et al (1993) Genetic relatedness of hepatitis $B$ viral strains of diverse geographical origin and natura variations in the primary structure of the surface antigen. J Gen Virol 74: 1341 1348

6. Bowyer SM, Van Staden L, Kew MC, Sim JG, et al. (1997) A unique segment of the hepatitis B virus group A genotype identified in isolates from South Africa. J Gen Virol 78: 1719-29.

7. Nakano T, Lu L, Hu X, Mizokami M, Orito E, et al. (2001) Characterization of hepatitis B virus genotypes among Yucpa Indians in Venezuela. J Gen Virol 82: $359-365$

8. Stuyver L, De Gendt S, Van Geyt C, Zoulim F, Fried M, et al. (2000) A new genotype of hepatitis $B$ virus: complete genome and phylogenetic relatedness. J Gen Virol 81: 67-74.

9. Norder H, Courouce AM, Coursaget P, Echevarria JM, Lee SD, et al. (2004 
Citation: Iqbal J, Raza A, Khattak JZK (2016) HBV Genotyping and Phylogenetic Analysis through Multiplex PCR Using Type Specific Primer Pairs in Pakistani Population. J Bacteriol Parasitol 7: 276. doi:10.4172/2155-9597.1000276

Genetic diversity of hepatitis B virus strains derived worldwide: genotypes, subgenotypes, and HBsAg subtypes. Intervirology 47: 289-309.

10. Zhang H, Zhai Y, Hu Z, Wu C, Qian J, et al. (2010) Genome-wide association study identifies 1p36.22 as a new susceptibility locus for hepatocellular carcinoma in chronic hepatitis B virus carriers. Nat Genet 42: 755-758.

11. Bagchi A, Mills AA (2008) The quest for the $1 \mathrm{p} 36$ tumor suppressor. Cancer Res 68: 2551-2556.

12. Stacey SN, Gudbjartsson DF, Sulem P, Bergthorsson JT, Kumar R, et al. (2008) Common variants on 1p36 and 1q42 are associated with cutaneous basal cell carcinoma but not with melanoma or pigmentation traits. Nat Genet 40: 1313 1318.

13. Preikschat P, Gunther S, Reinhold S, Will H, Budde K, et al. (2002) Complex HBV populations with mutations in core promoter, $\mathrm{C}$ gene, and pre-S region are associated with development of cirrhosis in long-term renal transplant recipients. Hepatology 35: 466-477.

14. Ferns RB, Naoumov NV, Gilson RJ, Tedder RS (2007) Presence of hepatitis $B$ virus core promoter mutations pre-seroconversion predict persistent viral replication after HBeAg loss. J Clin Virol 39: 199-204.

15. Zhu P, Tan D, Peng Z, Liu F, Song L (2007) Polymorphism analyses of hepatitis $B$ virus $X$ gene in hepatocellular carcinoma patients from southern China. Acta Biochim Biophys Sin (Shanghai) 39: 265-272.

16. Liu XH, Lin J, Zhang SH, Zhang SM, Feitelson MA, et al. (2008) COOH terminal deletion of $\mathrm{HBx}$ gene is a frequent event in HBV-associated hepatocellular carcinoma. World J Gastroenterol 14: 1346-1352.

17. Hung JH, Su IJ, Lei HY, Wang HC, Lin WC, et al. (2004) Endoplasmic reticulum stress stimulates the expression of cyclooxygenase-2 through activation of NFkappaB and pp 38 mitogen-activated protein kinase. J Biol Chem 279: 4638446392.

18. Wang LH, Huang W, Lai MD, Su IJ (2012) Aberrant cyclin A expression and centrosome overduplication induced by hepatitis $B$ virus pre-S2 mutants and its implication in hepatocarcinogenesis. Carcinogenesis 33: 466-472.

19. Payungporn S, Tangkijvanich $P$, Jantaradsamee $P$, Theamboonlers $A$, Poovorawan $Y$ (2004) Simultaneous quantitation and genotyping of hepatitis $\mathrm{B}$ virus by real-time PCR and melting curve analysis. J Virol Methods 120 $131-140$.

20. Yeh SH, Tsai CY, Kao JH, Liu CJ, Kuo TJ, et al. (2004) Quantification and genotyping of hepatitis $B$ virus in a single reaction by real-time PCR and melting curve analysis. J Hepatol 41: 659-666.
21. Grandjacques C, Pradat P, Stuyver L, Chevallier M, Chevallier P, et al. (2000) Rapid detection of genotypes and mutations in the pre-core promoter and the pre-core region of hepatitis $B$ virus genome: correlation with viral persistence and disease severity. J Hepatol 33: 430-439.

22. Mizokami M, Nakano T, Orito E, Tanaka Y, Sakugawa H, et al. (1999) Hepatitis $B$ virus genotype assignment using restriction fragment length polymorphism patterns. FEBS Lett 450: 66-71.

23. Naito H, Hayashi S, Abe K (2001) Rapid and specific genotyping system for hepatitis $B$ virus corresponding to six major genotypes by PCR using typespecific primers. J Clin Microbiol 39: 362-364.

24. Usuda S, Okamoto H, Tanaka T, Kidd-Ljunggren K, Holland PV, et al. (2000) Differentiation of hepatitis $B$ virus genotypes $D$ and $E$ by ELISA using monoclonal antibodies to epitopes on the preS2-region product. J Virol Methods 87: 81-89.

25. Trugene HBV Genotyping Assay (RUO) (2010) Siemens Medical Solutions Diagnostics, Tarrytown, NY, USA.

26. World Health Organisation (WHO) (2002) The hepatitis B virus, WHO/CDS CSR/LYO/2002.2:

27. Gasnereau I, Boissan M, Margall-Ducos G, Couchy G, Wendum D, et al (2012) KIF20A mRNA and its product MKIp2 are increased during hepatocyte proliferation and hepatocarcinogenesis. Am J Pathol 180: 131-140.

28. Feitelson MA, Larkin JD (2001) New animal models of hepatitis B and C. ILAR J 42: 127-138.

29. Marcellin P, Lau GK, Bonino F, Farci P, Hadziyannis S, et al. (2004) Peginterferon alfa-2a alone, lamivudine alone, and the two in combination in patients with HBeAg-negative chronic hepatitis B. N Engl J Med 351: 1206-1217.

30. Wang Z, Huang Y, Wen S, Zhou B, Hou J (2007) Hepatitis B virus genotypes and subgenotypes in China. Hepatol Res 37: 36-41.

31. Chan HL, Wong VW, Tse AM, Tse CH, Chim AM, et al. (2007) Serum hepatitis surface antigen quantitation can reflect hepatitis $B$ virus in the liver and predict treatment response. Clin Gastroenterol Hepatol 5: 1462-1468.

32. Bartholomeusz A, Schaefer S (2004) Hepatitis B virus genotypes: comparison of genotyping methods. Rev Med Virol 14: 3-16.

33. Iqbal J, Raza A, Din I, Khattak JZK (2015) Assessment of Occurrence of Hepatitis B Virus Genotypes among Population in Provisional Capital and Federal Capital of Pakistan. BMRJ 10: 1-8. 